\title{
PREOPERATIVE RADIOTHERAPY COMBINED WITH TOTAL MESORECTAL EXCISION FOR RESECTABLE RECTAL CANCER
}

\author{
Ellen Kapiteijn, M.D., Corrie A.M. Marijnen, M.D., Iris D. Nagtegaal, M.D., Hein Putter, Ph.D., \\ Willem H. Steup, M.D., Ph.D., Theo Wiggers, M.D., Ph.D., Harm J.T. Rutten, M.D., Ph.D., \\ Lars Pahlman, M.D., Ph.D., Bengt Glimelius, M.D., Ph.D., J. Han J.M. van Krieken, M.D., Ph.D., \\ Jan W.H. Leer, M.D., Ph.D., and Cornelis J.H. van de Velde, M.D., Ph.D., \\ for the Dutch Colorectal Cancer Group*
}

\begin{abstract}
Background Short-term preoperative radiotherapy and total mesorectal excision have each been shown to improve local control of disease in patients with resectable rectal cancer. We conducted a multicenter, randomized trial to determine whether the addition of preoperative radiotherapy increases the benefit of total mesorectal excision.
\end{abstract}

Methods We randomly assigned 1861 patients with resectable rectal cancer either to preoperative radiotherapy ( $5 \mathrm{~Gy}$ on each of five days) followed by total mesorectal excision (924 patients) or to total mesorectal excision alone (937 patients). The trial was conducted with the use of standardization and qualitycontrol measures to ensure the consistency of the radiotherapy, surgery, and pathological techniques.

Results Of the 1861 patients randomly assigned to one of the two treatment groups, 1805 were eligible to participate. The overall rate of survival at two years among the eligible patients was 82.0 percent in the group assigned to both radiotherapy and surgery and 81.8 percent in the group assigned to surgery alone $(P=0.84)$. Among the 1748 patients who underwent a macroscopically complete local resection, the rate of local recurrence at two years was 5.3 percent. The rate of local recurrence at two years was 2.4 percent in the radiotherapy-plus-surgery group and 8.2 percent in the surgery-only group $(P<0.001)$.

Conclusions Short-term preoperative radiotherapy reduces the risk of local recurrence in patients with rectal cancer who undergo a standardized total mesorectal excision. (N Engl J Med 2001;345:638-46.)

Copyright (c) 2001 Massachusetts Medical Society.

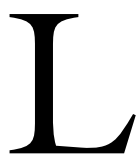

OCAL recurrence is a serious problem in the treatment of rectal cancer, since it causes disabling symptoms and is difficult to treat. ${ }^{1,2}$ There is a high incidence of local recurrence ( 15 to 45 percent) after conventional surgery, in which blunt dissection of the rectal fascia often fails to remove all the tissue that may bear tumor. ${ }^{3-5}$

In an attempt to improve local control and survival after conventional surgery, radiotherapy has been given. The only randomized trial that compared preoperative and postoperative radiotherapy showed the superiority of preoperative radiotherapy for local control. ${ }^{6}$ The Swedish Rectal Cancer Trial found that preoperative radiotherapy also improved the rate of survival at five years. ${ }^{7}$ A recent meta-analysis ${ }^{8}$ conclud- $^{-}$ ed that the combination of preoperative radiotherapy and surgery, as compared with surgery alone, significantly improved overall survival and cancer-specific survival.

The recognition that involvement of the circumferential margin by tumor cells is important in local recurrences has led to the general use of total mesorectal excision, ${ }^{9-13}$ in which the entire mesorectum is enveloped and resected by precise, sharp dissection. Improvements in local control with this technique have been shown, mainly in retrospective series.9-12,14

In previous studies of radiotherapy for rectal cancer, surgery was not standardized. Since surgical technique is a key factor in the success of tumor control, ${ }^{15-17}$ standardization and quality control with respect to surgery are indispensable for evaluating the effects of adjuvant therapy. Optimal quality must also include the use of standardized methods of pathological examination. ${ }^{18}$ A prospective, randomized trial was organized by the Dutch Colorectal Cancer Group to investigate the efficacy of preoperative radiotherapy in combination with standardized total mesorectal excision in patients with rectal cancer. ${ }^{19}$ In this article, we present the results of the trial after a median follow-up of two years.

\section{METHODS}

\section{Eligibility, Randomization, and Sample Size}

Patients were enrolled between January 1996 and December 1999. To be eligible, patients had to have histologically confirmed adenocarcinoma of the rectum, without evidence of distant metastases, and the inferior margin of the tumor had to be located not farther than $15 \mathrm{~cm}$ from the anal verge and below the level of S1-2. Patients with fixed tumors or tumors that were treated

From the Departments of Surgery (E.K., C.J.H.V.), Clinical Oncology (C.A.M.M.), and Medical Statistics (H.P.), Leiden University Medical Center, Leiden; the Departments of Pathology (I.D.N., J.H.J.M.K.) and Radiotherapy (J.W.H.L.), University Medical Center St. Radboud, Nijmegen; the Department of Surgery, Leyenburg Hospital, The Hague (W.H.S.); the Department of Surgery, University Hospital Groningen, Groningen (T.W.); and the Department of Surgery, Catharina Hospital, Eindhoven (H.J.T.R.) - all in the Netherlands; and the Departments of Surgery (L.P.) and Oncology (B.G.), Akademiska Sjukhuset, Uppsala, Sweden. Address reprint requests to Dr. van de Velde at the Department of Surgery K6-R, Leiden University Medical Center, P.O. Box 9600, 2300 RC Leiden, the Netherlands, or at velde@lumc.nl.

${ }^{*}$ Other participating investigators are listed in the Appendix. 
by local (transanal) resection were excluded. Patients with previous or coexisting cancer and those who had previously undergone largebowel surgery, chemotherapy, or radiotherapy of the pelvis were also excluded.

After informed consent had been obtained, we randomly assigned the patients to treatment with preoperative radiation (5 Gy on each of five days) followed by total mesorectal excision or to total mesorectal excision alone. Randomization was performed at the central trial office and was based on permuted blocks of six, with stratification according to center and the expected type of operation (low anterior resection or abdominoperineal resection). The trial was approved by the medical ethics committees of all the participating hospitals. The trial design and the calculation of the sample size have been described in detail elsewhere. ${ }^{19}$

\section{Follow-up}

Clinical evaluation every three months during the first year after surgery and yearly thereafter for at least two more years was mandatory and included yearly liver imaging and endoscopy. Local recurrence was defined as evidence of a tumor within the lesser pelvis or the perineal wound. Distant recurrence was defined as evidence of a tumor in any other area. Recurrence at the colostomy site or in the inguinal region was also classified as distant recurrence.

\section{Quality Control}

In the Netherlands, participating surgeons attended workshops and symposiums, saw instructional videotapes, and were monitored by specially trained instructor surgeons. At each hospital, the first five total mesorectal excisions were supervised by an instructor surgeon. ${ }^{19}$ Pathologists were trained to identify lateral spread of tumor according to the protocol of Quirke et al. ${ }^{18}$ The results of histopathological examination of the specimens were reviewed by a panel of supervising pathologists and a quality manager. ${ }^{20} \mathrm{~Pa}-$ tients' eligibility and treatment and the details of follow-up were checked by study coordinators. Local and distant recurrences were confirmed radiologically or histologically and checked by a radiation oncologist.

In Sweden, the technique of total mesorectal excision was introduced on a national basis several years ago, ${ }^{12,13}$ as was the protocol of Quirke et al. ${ }^{18}$ The European Organization for Research and Treatment of Cancer participated in this trial under protocol 40971. Visits to other participating hospitals and specialists were made before the start of the trial to ensure the quality of treatment at those sites. For logistic reasons, no quality control with respect to radiotherapy, surgery, or pathological examination was performed outside the Netherlands during the trial.

\section{Statistical Analysis}

Case-report forms were sent to the central trial office, where information on the forms was entered into a data base and analyzed with SPSS statistical software (version 9.0 for Windows, SPSS, Chicago). Chi-square tests were used to compare proportions. Mann-Whitney tests were used to compare quantitative and ordinal variables. Univariate analyses of survival were carried out by the Kaplan-Meier method, and the evaluation of differences between the two groups was performed with the log-rank test. The Cox proportional-hazards model was used to calculate hazard ratios and 95 percent confidence intervals in the univariate and multivariate analyses. A two-sided P value of 0.05 or less was considered to indicate statistical significance.

The starting point for the analyses of survival and recurrence was the day of surgery. Data on patients who were alive or free of recurrence were censored at the time of the last follow-up. The analysis of overall survival was performed on an intention-to-treat basis and thus included all the eligible patients. The rate of local recurrence was calculated on the basis of the number of eligible patients who underwent a macroscopically complete local resection. The rate of distant recurrence was calculated on the basis of the number of eligible patients who did not have distant metastasis at the time of surgery. The overall rate of recurrence was calculated on the basis of the number of eligible patients who had macroscopically complete local resection without distant metastasis. Analyses of postoperative morbidity and mortality were based on the total number of eligible patients who underwent resection.

\section{RESULTS}

\section{Patients}

A total of 1861 patients were randomly assigned to one of the two treatment groups. There were 1530 patients from 84 Dutch hospitals, 228 from 13 Swedish hospitals, and 103 from 11 other European and Canadian centers. Of these 1861 patients, a total of 56 were found to be ineligible before randomization, including 4 patients for whom there was no information on eligibility. Our analysis therefore included 1805 eligible patients. Of these, 1653 patients had a curative resection. Of the remaining 152 patients, 57 did not undergo a macroscopically complete local resection, and 95 were found to have distant metastasis at surgery (Table 1). The characteristics of the 1805 patients who were eligible for the study and the features of their tumors were similar in the two treatment groups (Table 2 ). In 28 patients ( 2 percent), no tumor was found in the resected specimen, despite a preoperative biopsy that showed an adenocarcinoma.

\section{Protocol Violations}

Patients with major or minor protocol violations, or both, were included in all the analyses.

\section{Major Violations}

Of the 897 eligible patients assigned to undergo radiotherapy before total mesorectal excision, 29 did not receive preoperative radiotherapy for the following reasons: known metastases ( 8 patients), carcinoma in situ (1), sigmoid carcinoma (3), a second cancer (1), withdrawal of informed consent (11), and physical limitations that made radiotherapy impossible (5). Long-term preoperative radiotherapy was given to seven patients for locally advanced tumors. One patient was unable to tolerate surgery and was treated with long-term radiotherapy alone. Preoperative radiotherapy was discontinued in 14 patients, mainly because of neurotoxicity.

Of the 908 eligible patients assigned to total mesorectal excision alone, 3 patients withdrew their informed consent and requested radiotherapy (5 Gy on each of five days), and 8 patients had advanced local tumors for which long-term preoperative radiotherapy was given.

Postoperative adjuvant therapy was not allowed in patients who had microscopically tumor-free margins without spillage of tumor cells during the operation. Of 1759 eligible patients with available information on margins and tumor spillage, 1351 (77 percent) had tumor-free margins without tumor spillage. Eightyfive of these patients (38 in the group assigned to radiotherapy and surgery and 47 in the group assigned to surgery alone) received adjuvant therapy (chemo- 
Table 1. Characteristics of the Eligible and Ineligible Patients and Rates of Macroscopically Complete local Resection, According to Treatment Group. *

\begin{tabular}{|c|c|c|c|}
\hline \multirow[t]{2}{*}{ VARIABLE } & \multirow[t]{2}{*}{$\begin{array}{c}\text { AlL } \\
\text { Patients }\end{array}$} & \multicolumn{2}{|c|}{ Treatment Group } \\
\hline & & $\begin{array}{l}\text { RADIOTHERAPY } \\
\text { PLUS SURGERY }\end{array}$ & $\begin{array}{l}\text { SURGERY } \\
\text { ALONE }\end{array}$ \\
\hline & & no. (\%) & \\
\hline Randomly assigned to treatment & 1861 & 924 & 937 \\
\hline Ineligible for participation & 56 & 27 & 29 \\
\hline No adenocarcinoma & 8 & 5 & 3 \\
\hline Fixed tumor & 2 & 0 & 2 \\
\hline Tumor treated by transanal resection & 2 & 2 & 0 \\
\hline Tumor $>15 \mathrm{~cm}$ from anal verge & 5 & 4 & 1 \\
\hline Previous cancer & 21 & 8 & 13 \\
\hline Coexisting cancer & 11 & 4 & 7 \\
\hline $\begin{array}{l}\text { Previous large-bowel surgery, pelvic radiotherapy, } \\
\text { or chemotherapy }\end{array}$ & 3 & 2 & 1 \\
\hline No information on eligibility & 4 & 2 & 2 \\
\hline Eligible for participation & $1805(97)$ & $897(97)$ & $908(97)$ \\
\hline Incomplete local resection & & & \\
\hline Without distant metastases & 31 & 10 & 21 \\
\hline With distant metastases & 26 & 14 & 12 \\
\hline Complete local resection & $1748(94)$ & $873(94)$ & $875(93)$ \\
\hline With distant metastases & 95 & 47 & 48 \\
\hline Without distant metastases (curative) & $1653(89)$ & $826(89)$ & $827(88)$ \\
\hline
\end{tabular}

*Percentages are based on the total numbers of patients randomly assigned to one of the two treatment groups.

Table 2. Characteristics of the 1805 Eligible Patients.*

\begin{tabular}{|c|c|c|c|}
\hline CHARACtERISTIC & $\begin{array}{l}\text { RADIOTHERAPY } \\
\text { PLUS SURGERY } \\
\text { (N=897) }\end{array}$ & $\begin{array}{l}\text { SURGERY ALONE } \\
(\mathbf{N}=908)\end{array}$ & $\begin{array}{c}P \\
V_{A L U E}\end{array}$ \\
\hline Age - yr & & & 0.79 \\
\hline Median & 65 & 66 & \\
\hline Range & $26-88$ & $23-92$ & \\
\hline Sex - no. $(\%)$ & & & 0.92 \\
\hline Male & $573(64)$ & $578(64)$ & \\
\hline Female & $324(36)$ & $330(36)$ & \\
\hline $\begin{array}{l}\text { Distance of tumor from } \\
\text { anal verge - no. (\%) }\end{array}$ & & & 0.48 \\
\hline $10.1-15 \mathrm{~cm}$ & $267(30)$ & $280(31)$ & \\
\hline $5.1-10 \mathrm{~cm}$ & $384(43)$ & $364(40)$ & \\
\hline$\leqslant 5 \mathrm{~cm}$ & $244(27)$ & $263(29)$ & \\
\hline Unknown & $2(<1)$ & $1(<1)$ & \\
\hline Type of resection - no. (\%) & & & 0.12 \\
\hline None & $16(2)$ & $29(3)$ & \\
\hline Low anterior & $579(65)$ & $604(67)$ & \\
\hline Abdominoperineal & $251(28)$ & $234(26)$ & \\
\hline Hartmann $\dagger$ & $50(6)$ & $40(4)$ & \\
\hline Unknown & $1(<1)$ & $1(<1)$ & \\
\hline TNM stage — no. (\%) & & & 0.53 \\
\hline 0 & $11(1)$ & $17(2)$ & \\
\hline I & $265(30)$ & $244(27)$ & \\
\hline II & $252(28)$ & $245(27)$ & \\
\hline III & $300(33)$ & $324(36)$ & \\
\hline IV & $61(7)$ & $61(7)$ & \\
\hline Unknown or no resection & $8(<1)$ & $17(2)$ & \\
\hline
\end{tabular}

*Characteristics were unknown in some cases because not all case-report forms were received. Because of rounding, not all percentages total 100 . TNM denotes tumor-node-metastasis.

†A Hartmann resection is a low anterior resection without the construction of an anastomosis. therapy, radiotherapy, or chemoradiotherapy), which was a major protocol violation.

\section{Minor Violations}

Of the 846 eligible patients randomly assigned to preoperative radiotherapy who received the total dose of $25 \mathrm{~Gy}$, the interval between the first day of radiotherapy and the day of surgery exceeded 10 days in 110 patients ( 13 percent). In 127 of the patients ( 15 percent), the upper border of the treatment field was at the level of $S 1-2$ instead of at the promontory, and in 161 of the patients undergoing an abdominoperineal resection (19 percent), the perineum was not included in the treated volume.

\section{Postoperative Morbidity and Mortality}

The median interval between randomization and surgery was 21 days in the group assigned to radiotherapy and surgery and 14 days in the group assigned to surgery alone. The patients assigned to radiotherapy and surgery lost slightly more blood during the operation than those assigned to surgery alone (median loss, 1000 vs. $900 \mathrm{ml} ; \mathrm{P}<0.001$ ), and of the patients who had an abdominoperineal resection, those assigned to radiotherapy had more perineal complications than those assigned to surgery alone (26 percent vs. 18 percent, $\mathrm{P}=0.05)$. No other significant differences with respect to postoperative morbidity and mortality were found between the two groups. 


\section{Follow-up}

As of February 2001, surviving eligible patients without local recurrence had been followed for a median of 24.9 months (range, 1.1 to 56.0). Of these patients, 87 percent were followed for at least one year, 54 percent for at least two years, 24 percent for at least three years, and 5 percent for at least four years. Rates of survival and recurrence are presented here at a follow-up of two years. A reanalysis as of June 1, 2001 , produced essentially the same results for all the major end points of the study.

\section{Events}

As of February 2001, 365 (20 percent) of the 1805 eligible patients had died. Of the 365 deaths, 61 occurred postoperatively, 231 were related to rectal cancer (growth of the primary tumor [in cases of macroscopically incomplete resection] or recurrence), and 70 were not related to rectal cancer. In three patients, the cause of death was unknown.

Local recurrence occurred in 87 patients. Of these 87 patients, 45 (52 percent) had local recurrence alone, 28 ( 32 percent) had both local and distant recurrences, and 14 (16 percent) had local recurrence after distant metastasis was found at surgery (in 9 patients) or during follow-up (in 5). A total of 227 patients were found to have only distant recurrence.

\section{Overall Survival}

The rate of overall survival at two years was 82.0 percent in the group assigned to radiotherapy before surgery and 81.8 percent in the group assigned to surgery alone $(\mathrm{P}=0.84)$ (Fig. 1$)$. The hazard ratio for death in the group assigned to surgery alone as compared with the group assigned to preoperative radiotherapy was 1.02 (95 percent confidence interval, 0.83 to 1.25 ).

\section{Local Recurrence}

The rate of local recurrence at two years was 5.3 percent in the population of 1748 patients who underwent a macroscopically complete local resection. The rates of local recurrence at two years were 2.4 percent in the group assigned to radiotherapy before surgery and 8.2 percent in the group assigned to surgery alone $(\mathrm{P}<0.001)$ (Fig. 2). According to a univariate analysis, the hazard ratio for local recurrence in the group assigned to surgery alone as compared with the group assigned to preoperative radiotherapy plus surgery was 3.42 (95 percent confidence interval, 2.05 to 5.71$)$.

In the univariate analyses, treatment-group assignment $(\mathrm{P}<0.001)$, the location of the tumor (distance of the tumor from the anal verge $)(P=0.003)$, and the tumor-node-metastasis $(\mathrm{TNM})$ stage $(\mathrm{P}<0.001)$

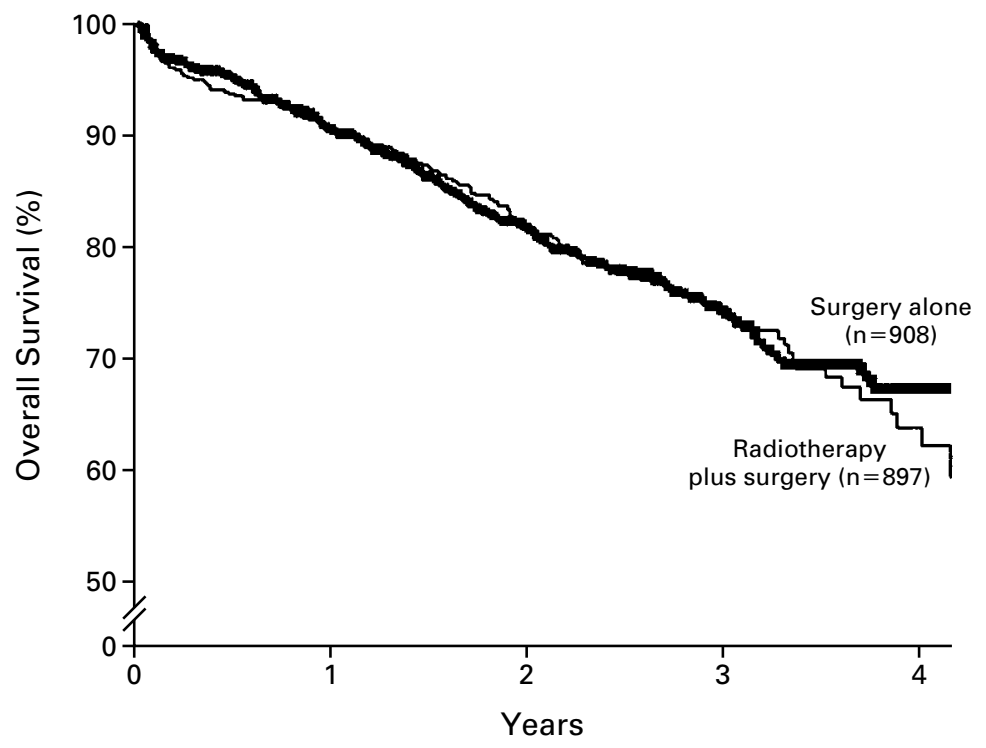

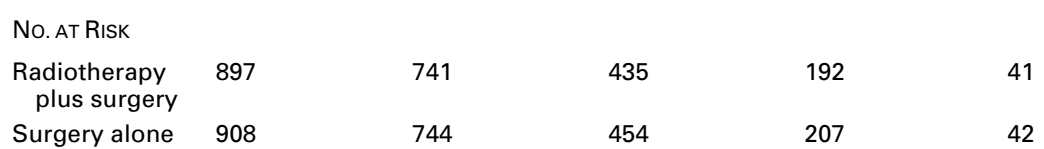

Figure 1. Rates of Overall Survival in the Population of 1805 Eligible Patients, According to Treatment Group.

At two years, the rate of overall survival was 82.0 percent in the group assigned to radiotherapy and surgery and 81.8 percent in the group assigned to surgery alone $(P=0.84)$. 


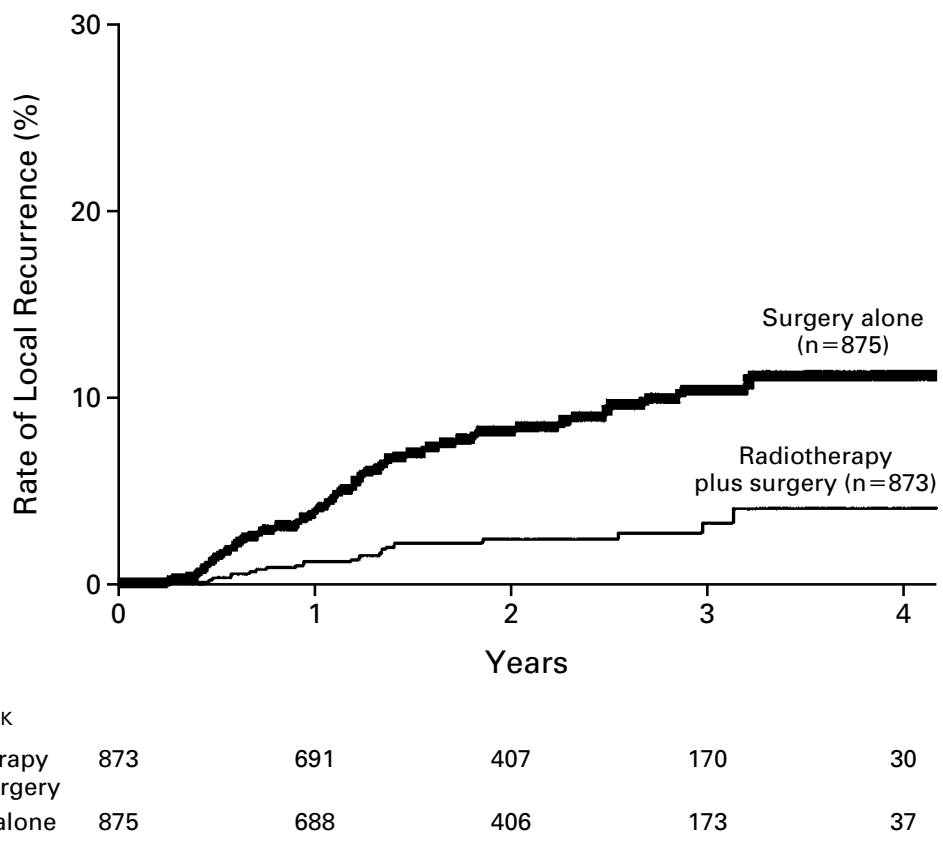

Figure 2. Rates of Local Recurrence in the Population of 1748 Eligible Patients Who Underwent Macroscopically Complete Local Resection, According to Treatment Group.

At two years, the rate of local recurrence was 2.4 percent in the group assigned to radiotherapy and surgery and 8.2 percent in the group assigned to surgery alone $(P<0.001)$.

were significant predictors of the risk of local recurrence. In the multivariate Cox regression analysis (Table 3$)$, the treatment-group assignment $(\mathrm{P}<0.001)$, the tumor location $(\mathrm{P}=0.03)$, and the TNM stage $(\mathrm{P}<0.001)$ were independent predictors of the risk of local recurrence, whereas the type of resection $(\mathrm{P}=0.90)$ had no independent prognostic value with respect to this end point.

Univariate subgroup analyses showed that preoperative radiotherapy reduced the risk of local recurrence significantly in patients who had tumors with an inferior margin less than or equal to $5 \mathrm{~cm}(\mathrm{P}=$ $0.05)$ or 5.1 to $10 \mathrm{~cm}(\mathrm{P}<0.001)$ from the anal verge (Table 4). Radiotherapy had no significant effect on tumors located 10.1 to $15 \mathrm{~cm}$ from the anal verge $(\mathrm{P}=0.17)$. For TNM stage II and III tumors, preoperative radiotherapy had a significant beneficial effect $(\mathrm{P}=0.01$ and $\mathrm{P}<0.001$, respectively), which was not observed for TNM stage I and IV tumors $(\mathrm{P}=$ 0.15 and $\mathrm{P}=0.25$, respectively). However, tests for interaction among the tumor location, TNM stage, and treatment-group assignment in a multivariate analysis showed no significant interaction between tumor location and treatment-group assignment $(\mathrm{P}=$ 0.08 ) or between the TNM stage and treatmentgroup assignment $(\mathrm{P}=0.61)$, suggesting that the treat-
Table 3. Results of Multivariate Cox Regression Analysis of Local Recurrence among the 1748 Eligible Patients with a Macroscopically Complete Local Resection.*

\begin{tabular}{|c|c|c|}
\hline VARIABLE & HAZARD RATIO $(95 \%$ Cl) & P Value \\
\hline Treatment group & & $<0.001$ \\
\hline Radiotherapy and surgery & 1.00 & \\
\hline Surgery alone & $3.41(2.05-5.70)$ & \\
\hline Distance of tumor from anal verge & & 0.03 \\
\hline $10.1-15 \mathrm{~cm}$ & 1.00 & \\
\hline $5.1-10 \mathrm{~cm}$ & $2.13(1.13-4.01)$ & 0.02 \\
\hline$\leqslant 5 \mathrm{~cm}$ & $2.78(1.22-6.31)$ & 0.02 \\
\hline Type of resection & & 0.90 \\
\hline Low anterior & 1.00 & \\
\hline Abdominoperineal & $1.15(0.59-2.24)$ & 0.68 \\
\hline Hartmann $\dagger$ & $1.16(0.42-3.25)$ & 0.78 \\
\hline TNM stage & & $<0.001$ \\
\hline I & 1.00 & \\
\hline II & $3.44(1.26-9.39)$ & 0.02 \\
\hline III & $9.69(3.89-24.2)$ & $<0.001$ \\
\hline $\begin{array}{l}\text { IV (distant metastases but complete } \\
\text { local resection) }\end{array}$ & $16.2(5.40-48.6)$ & $<0.001$ \\
\hline
\end{tabular}

${ }^{*} \mathrm{~A}$ variable was included in the multivariate analysis if its $P$ value in the univariate analysis was less than 0.10 . Patients with missing data were excluded from the analysis of local recurrence. Twenty-eight patients without a tumor (TNM stage 0 ) were excluded from the multivariate analysis because they were not at risk for local recurrence. CI denotes confidence interval and TNM tumor-node-metastasis.

†A Hartmann resection is a low anterior resection without the construction of an anastomosis. 


\begin{tabular}{|c|c|c|c|c|c|}
\hline $\begin{array}{r}\text { TABLe 4. Results of } \\
\text { OF LOCAl Red } \\
\text { WITH a MA } \\
\text { ACCORDI }\end{array}$ & $\begin{array}{l}\text { IVARIATE LC } \\
\text { RENCE AMOI } \\
\text { COPICALLY } \\
\text { TO SELECTE }\end{array}$ & $\begin{array}{l}\text { G-RANK ANAI } \\
\text { NG THE } 1748 \\
\text { COMPLETE LO } \\
\text { D PROGNOSTIC }\end{array}$ & $\begin{array}{l}\text { ISES OF T } \\
\text { LIGIBLE I } \\
\text { CAL RESE } \\
\text { VARIABLI }\end{array}$ & $\begin{array}{l}\text { WO-YEAR I } \\
\text { PATIENTS } \\
\text { CTION, } \\
\text { ES. }{ }^{*}\end{array}$ & \\
\hline \multirow[t]{3}{*}{ VARIABLE } & \multicolumn{2}{|c|}{ RADIOTHERAPY PLUS SURGERY } & \multicolumn{2}{|c|}{ Surgery Alone } & \multirow[t]{3}{*}{ P Value } \\
\hline & \multirow[t]{2}{*}{$\begin{array}{l}\text { NO. OF } \\
\text { PATIENTS } \\
\text { AT RISK }\end{array}$} & $\begin{array}{c}\text { LOCAL } \\
\text { RECURRENCE } \\
\text { AT } 2 \text { YR }\end{array}$ & $\begin{array}{l}\text { NO. OF } \\
\text { PATIENTS } \\
\text { AT RISK }\end{array}$ & $\begin{array}{c}\text { LOCAL } \\
\text { RECURRENCE } \\
\text { AT } 2 \text { YR }\end{array}$ & \\
\hline & & $\%$ & & $\%$ & \\
\hline Overall & 873 & 2.4 & 875 & 8.2 & $<0.001$ \\
\hline \multicolumn{6}{|l|}{ Sex } \\
\hline Male & 555 & 2.5 & 557 & 7.2 & $<0.001$ \\
\hline Female & 318 & 2.2 & 318 & 9.8 & $<0.001$ \\
\hline \multicolumn{6}{|l|}{ Distance of tumor from anal verge } \\
\hline $10.1-15 \mathrm{~cm}$ & 262 & 1.3 & 271 & 3.8 & 0.17 \\
\hline $5.1-10 \mathrm{~cm}$ & 372 & 1.0 & 350 & 10.1 & $<0.001$ \\
\hline$\leqslant 5 \mathrm{~cm}$ & 237 & 5.8 & 253 & 10.0 & 0.05 \\
\hline \multicolumn{6}{|l|}{ Type of resection } \\
\hline Low anterior & 577 & 1.2 & 603 & 7.3 & $<0.001$ \\
\hline Abdominoperineal & 248 & 4.9 & 232 & 10.1 & 0.02 \\
\hline Hartmann $†$ & 47 & 3.2 & 39 & 10.7 & 0.18 \\
\hline \multicolumn{6}{|l|}{ TNM stage } \\
\hline I & 265 & 0.5 & 244 & 0.7 & 0.15 \\
\hline II & 251 & 1.0 & 241 & 5.7 & 0.01 \\
\hline III & 298 & 4.3 & 324 & 15.0 & $<0.001$ \\
\hline $\begin{array}{l}\text { IV (distant metastases but } \\
\text { complete local resection) }\end{array}$ & 47 & 10.1 & 48 & 23.8 & 0.25 \\
\hline
\end{tabular}

* Patients with missing data were excluded from the analysis of local recurrence. Twenty-eight patients without a tumor (TNM stage 0 ) were excluded from the multivariate analysis because they were not at risk for local recurrence. In a Cox proportional-hazards analysis of age (as a continuous variable), the hazard ratio for local recurrence at two years was 0.99 ( 95 percent confidence interval, 0.95 to $1.04 ; \mathrm{P}=0.77$ ) in the group of 873 patients assigned to radiotherapy and surgery and 1.01 (95 percent confidence interval, 0.99 to $1.04 ; \mathrm{P}=0.21$ ) in the group of 875 patients assigned to surgery alone. TNM denotes tumor-node-metastasis.

†A Hartmann resection is a low anterior resection without the construction of an anastomosis.

ment effect did not differ among the subgroups analyzed (data not shown).

\section{Distant Recurrence}

The rate of distant recurrence at two years was 14.8 percent in the group assigned to radiotherapy and surgery and 16.8 percent in the group assigned to surgery alone $(\mathrm{P}=0.87)$. The hazard ratio for distant recurrence in the surgery-only group as compared with the radiotherapy-plus-surgery group was 1.02 (95 percent confidence interval, 0.80 to 1.30 ).

\section{Overall Recurrence}

The overall rate of recurrence (the rate of local recurrence and distant recurrence) at two years was 16.1 percent in the group assigned to radiotherapy and surgery and 20.9 percent in the group assigned to surgery alone $(\mathrm{P}=0.09)$. The hazard ratio for any recurrence in the surgery-only group as compared with the radiotherapy-plus-surgery group was 1.21 (95 percent confidence interval, 0.97 to 1.52 ).

\section{DISCUSSION}

In this trial, we evaluated the efficacy of short-term preoperative radiotherapy combined with standardized total mesorectal excision in patients with resectable rectal cancer. We found that radiotherapy before total mesorectal excision can improve local control of disease.

Reported rates of local control after surgery for rectal cancer vary widely. In studies of conventional, nonstandardized surgery, usually with a minimal follow-up of five years, rates of local recurrence have been 15 to 45 percent. $^{3-5}$ By contrast, surgeons who specialize in total mesorectal excision report localrecurrence rates of 7 percent or less.9-11 The low rate of local recurrence in the group assigned to total mesorectal excision only in our study (8.2 percent at two years) demonstrates that similar excellent results can be achieved by other surgeons at multiple centers after they are trained in the procedure.

We found that preoperative radiotherapy further reduced the two-year rate of local recurrence from 
8.2 percent to 2.4 percent, an indication of the value of preoperative radiotherapy when used in conjunction with standardized surgery. In the Swedish Rectal Cancer Trial, the reduction in the rate of local recurrence at five years from 27 percent in the surgeryonly group to 11 percent in the radiotherapy-plussurgery group improved the rate of overall survival at this time point from 48 percent in the surgeryonly group to 58 percent in the combined-treatment group. ${ }^{7}$ An effect of preoperative radiotherapy on overall survival has not yet been detected in our trial, probably because of the small number of local recurrences and the short follow-up. However, we believe that a median follow-up time of 24.9 months is sufficient to detect the effect of preoperative radiotherapy on local recurrences, 55 to 80 percent of which occur during the first 2 years after surgery, with the peak rate at 6 to 12 months. ${ }^{4,21,22}$

The beneficial effect of preoperative radiotherapy in our trial was observed for all tumor locations $15 \mathrm{~cm}$ or less from the anal verge and for all TNM stages. However, in a univariate subgroup analysis, the effect was not significant in patients who had tumors with an inferior margin more than $10 \mathrm{~cm}$ from the anal verge and in patients who had TNM stage I or IV tumors. Nevertheless, multivariate tests indicated that the treatment effect probably did not differ among subgroups defined according to tumor location, TNM stage, and treatment assignment. Therefore, considering the difficulties involved in predicting the location of tumors high above the anal verge and in determining the TNM stage preoperatively, the decision not to irradiate before surgery should be carefully considered.

Preoperative radiotherapy does not result in "downstaging" 23 and is therefore not suitable for locally advanced tumors. To avoid short-term irradiation of such tumors, we advocate accurate preoperative imaging (for example, computed tomography or magnetic resonance imaging). This lack of down-staging explains why short-term preoperative radiotherapy has no effect on sphincter preservation, which is often an end point in conventional trials of long-term radiotherapy.

Concern has been expressed about the side effects of hypofractionated radiation. ${ }^{24}$ In the Stockholm I tri$\mathrm{al}^{25}$ and Imperial Cancer Research Fund trial, ${ }^{26}$ postoperative mortality was higher among patients who received radiotherapy than among those who did not. In both trials, a suboptimal irradiation technique increased the treated volume considerably. In the Swedish Rectal Cancer Trial, postoperative mortality did not increase with radiation, provided that radiotherapy was optimal. ${ }^{27}$ In our trial, there was no difference in in-hospital mortality between the two groups. In the Swedish Rectal Cancer Trial, however, there was more incontinence among patients who underwent preoperative irradiation and subsequently underwent a sphincter-preserving surgery. ${ }^{28}$

In conclusion, total mesorectal excision can signif- icantly decrease the risk of local recurrence of resectable rectal cancer. This result was achieved in a large, multicenter trial that included extensive instruction and quality control of the surgical technique. In this large group of patients who underwent standardized surgery, short-term preoperative radiotherapy further reduced the risk of local recurrence.

Supported by grants from the Dutch Cancer Society (CKVO 95-04), the Dutch National Health Council (OWG 97/026), and the Swedish Cancer Society.

\section{APPENDIX}

The following investigators participated in the study: the Netherlands - Surgeons: A.B. Bijnen and P. de Ruiter, Medisch Centrum Alkmaar; B. van Ooijen, Algemeen Christelijk Ziekenhuis Eemland, Amersfoort; D. van Geldere and R.P.A. Boom, Ziekenhuis Amstelveen, Amstelveen; R.P. Bleichrodt and S. Mever, Academisch Ziekenhuis Vrije Universiteit, Amsterdam; R.M.J.M. Butzelaar, E.P. Steller, W.F. van Tets, and A.C.H. Boissevain, Sint Lucas Andreas Ziekenhuis, Amsterdam; F.J. Sjardin, Bovenij Ziekenhuis, Amsterdam; J.F.M. Slors, Academisch Medisch Centrum, Amsterdam; W.H. Bouma and J.G.J. Roussel, Gelre Ziekenhuizen, Apeldoorn; J.H.G. Klinkenbijl and E.J. Spillenaar Bilgen, Ziekenhuis Rijnstate, Arnhem; P.M. Kruyt and W.K. de Roos, Stichting Ziekenhuisvoorzieningen Gelderse Vallei, Bennekom; E.J.R. Slingenberg and P.D. de Rooij, Sint Ziekenhuis Lievensberg, Bergen op Zoom; M.A.J.M. Hunfeld, Rode Kruis Ziekenhuis, Beverwijk; A.L.A. Meersman, Maasziekenhuis, Boxmeer; J.K.S. Nuytinck, Ignatius Ziekenhuis, Breda; R.M.P.H. Crolla, Ziekenhuis de Baronie, Breda; J. van der Bijl, Atrium Brunssum, Brunssum, and Atrium Heerlen, Heerlen; G.W.M. Tetteroo, Ijsselland Ziekenhuis, Capelle aan de Ijssel; L.P.S. Stassen and P.W. de Graaf, Reinier de Graaf Groep, Delft; W.A.H. Gelderman and F.G.J. Willekens, Bosch Medicentrum, den Bosch; I.P.T. van Bebber and E.J. Carol, Stichting Carolus-Liduina-Lindelust Ziekenhuis, den Bosch; G.W. Kastelein and H. Boutkan, Stichting Juliana Kinderziekenhuis-Rode Kruis Ziekenhuis, Den Haag; C. Ulrich and B.C. de Vries, Medisch Centrum Haaglanden, Den Haag; H.J. Smeets and J.M. Heslinga, Stichting Bronovo-Nebo, Ziekenhuis Bronovo, Den Haag; P.V.M. Pahlplatz, Ziekenhuis Leyenburg, Den Haag; P. Heres and J.A. van Oijen, Stichting het van Weel-Bethesda Ziekenhuis, Dirksland; M. van Hillo, Stichting Talma Sionsberg, Dokkum; R.J. Oostenbroek and K.G. Tan, Albert Schweitzer Ziekenhuis, Dordrecht; H.C.J. van der Mijle and R. Looijen, Christelijk Ziekenhuis Nij Smellinghe, Drachten; J.J. Jakimowicz, Catharina Ziekenhuis, Eindhoven; O.J. Repelaer van Driel and P.H.M. Reemst, Diaconessenhuis Eindhoven; E.J.T. Luiten and R.F.T.A. Assmann, Sint Annaziekenhuis, Geldrop; C.M. Dijkhuis, Oosterscheldeziekenhuis, Goes; R.T. Ottow, Het Groene Hart Ziekenhuis, Gouda; J.T.M. Plukker Academisch Ziekenhuis Groningen; E.J. Boerma and R. Silvis, Kennemer Gasthuis, Haarlem; J.H. Tomee, Stichting Streekziekenhuis CoevordenHardenberg, Hardenberg; G.J.M. Akkersdijk, Spaarne Ziekenhuis, Heemstede; C.G.B.M. Rupert, de Tjongerschans Ziekenhuis, Heerenveen; G.J.C.M. Niessen and G. Verspui, Elkerliek Ziekenhuis, Helmond; J.H. Kroesen and J.W. Juttmann, Ziekenhuis Hilversum, Hilversum; J.W.D. de Waard and M.W.C. de Jonge, Westfries Gasthuis, Hoorn; D.B.W. de Roy van Zuidewijn and W. Dahmen, Medisch Centrum Leeuwarden; R. Vree, J.A. Zonnevylle, Diaconessenhuis, Leiden; E. Klein Kranenbarg and R.A.E.M. Tollenaar, Leids Universitair Medisch Centrum, Leiden; P.A. Neijenhuis, S.A. da Costa, and S.K. Adhin, Rijnland Ziekenhuis, Leiderdorp; F.J. Idenburg, Medisch Centrum Haaglanden, Leidschendam; H. van der Veen and C.E.A.M. Hoynck van Papendrecht, IJsselmeerziekenhuizen, Lelystad; C.G.M.I. Baeten, M.F. von Meyenfeldt, and G.L. Beets, Academisch Ziekenhuis Maastricht; T. Wobbes, Academisch Ziekenhuis, Nijmegen Sint Radboud, Nijmegen; E.D.M. Bruggink and L.J.A. Strobbe, Canisius-Wilhelmina Ziekenhuis, Nijmegen; O.J. van West and R.A.J. Dörr, Pasteurziekenhuis, Oosterhout; C.D. van Duyn, Ziekenhuis Bernhoven, Oss; J.W.M. Bol and T.A.A. van den Broek, Waterlandziekenhuis, Purmerend; J.M.H. Debets and R.J.A. Estourgie, Laurentius Ziekenhuis, Roermond; H.W.P.M. Kemperman, Ziekenhuis Franciscus, Roosendaal; H.F. Veen, W.F. Weidema, and C.J. van Steensel, Ikazia Ziekenhuis, Rotterdam; F. Logeman and A.A.E.A. de Smet, Sint Clara Ziekenhuis, Rotterdam; A.W.K.S. Marinelli, Daniel den Hoed Kliniek, Rotterdam; J.H. Driebeek-van Dam, Havenziekenhuis, Rotterdam; W.R. Schouten and P.P.L.O. Coene, Academisch Ziekenhuis Rotterdam, Dijkzigt; M.A. Paul, Zuiderziekenhuis, Rotterdam; J.J. van Bruggen, Schieland Ziekenhuis, Schiedam; E.J. Mulder, Antonius Ziekenhuis, Sneek; R. den Toom and A.J. van Beek, Ruwaard van Putten Ziekenhuis, Spijkenisse; S.J. Brenninkmeyer 
and G.P. Gerritsen, Tweesteden Ziekenhuis, Tilburg; H.J.M. Oostvogel and J.A. Roukema, Sint Elisabeth Ziekenhuis, Tilburg; E.B.M. Theunissen, Mesos, Utrecht; L.W.M. Janssen and A. Hennipman, Universitair Medisch Centrum, Utrecht; A.J.M. van Wieringen, Mesos, Utrecht; A. Pronk and P. Leguit, Diakonessenhuis, Utrecht; F.A.A.M. Croiset van Uchelen and R.M.H. Roumen, Sint Joseph Ziekenhuis, Veldhoven; C.L.H. van Berlo and J.F.M. Reinders, Sint Maartens Gasthuis, Venlo; C.D.G.W. Verheij, Sint Elisabeth Ziekenhuis, Venray; J.H. ten Thije, Ziekenhuis Walcheren, Vlissingen; W. van Overhagen and I.H. Oei, Reinier de Graaf Groep, Voorburg; E.M.G. Leerkotte and J.W.A. van Luijt, Tweesteden Ziekenhuis, Waalwijk; H.C.M. Verkooyen and J.A.L. Jansen, Sint Jans-Gasthuis, Weert; J. Merkx and J.P. Vente, Hofpoort Ziekenhuis, Woerden; H. de Morree, Stichting Oosterscheldeziekenhuizen, Zierikzee; P.J.J. van Rijn, 't Lange Land Ziekenhuis, Zoetermeer; and W.F. Blom, Albert Schweitzer Ziekenhuis, Zwijndrecht; Pathologists: J.P.A. Baak, Medisch Centrum Alkmaar; H. Barrowclough, Algemeen Christelijk Ziekenhuis Eemland, Amersfoort; G.J.A. Offerhaus, Academisch Medisch Centrum, Amsterdam; G. Brutel de la Riviere, M.L.F. van Velthuysen, Antoni van Leeuwenhoekziekenhuis, Amsterdam; B.A. van de Wiel, Sint Lucas Andreas Ziekenhuis, Amsterdam; H.H. Oushoorn, Bovenij Ziekenhuis, Amsterdam; E. Bloemena, Vrije Universiteit, Amsterdam; T.A.J.M. Manschot, Gelre Ziekenhuizen, Apeldoorn; J.M. Wiersma-van Tilburg, Ziekenhuis Rijnstate, Arnhem; V. Potters, Stichting Ziekenhuis Lievensberg, Bergen op Zoom; H.V. Stel, Ziekenhuis Gooi-Noord, Blaricum; J. Los, Ignatius Ziekenhuis, Breda; G.W. Verdonk, Atrium Brunssum; C. van Krimpen, S.H. Sastrowijoto, and E.M. van der Loo, Stichting Diagnostisch Centrum Stichting Samenwerkende Delftse Ziekenhuizen, Delft; H.A. Meijer, Bosch Medicentrum, den Bosch; P. Blok, Ziekenhuis Levenburg, Den Haag; C.J. Tinga, Stichting BronovoNebo, Ziekenhuis Bronovo, Den Haag; E.C.M. Ooms, Medisch Centrum Haaglanden, Den Haag; C.M. Bruijn-van Duinen, Ziekenhuis Leyenburg, Den Haag; J.W. Steffelaar, Stichting Juliana Kinderziekenhuis-Rode Kruis Ziekenhuis, Den Haag; P.J. Westenend, Pathologisch Laboratorium voor Dordrecht en Omstreken, Dordrecht; I.W.N. Tan-Go and H.M. Peters, Stichting Pathologische Anatomie en Medische Microbiologie, Eindhoven; E.J.M. Ahsmann, Stichting Laboratoria Goudse Ziekenhuizen, Gouda; J.F. Keuning, Stichting Pathologisch Anatomisch Laboratorium Kennemerland, Haarlem; K. van Groningen, Spaarne Ziekenhuis, Heemstede; P.H.M.H. Theunissen, Atrium Heerlen, Heerlen; F.J.J.M. van Merrienboer, Elkerliek Ziekenhuis, Helmond; G. Freling, Ziekenhuis Bethesda, Hoogeveen; A.J.K. Grond, Laboratorium voor de Volksgezondheid in Friesland, Leeuwarden; M.C.B. Gorsira, Diaconessenhuis, Leiden; J.J. Calame, Rijnland Ziekenhuis, Leiderdorp; E.A. Neefjes-Borst, IJsselmeerziekenhuizen, Lelystad; J.W. Arends, Academisch Ziekenhuis, Maastricht; A.P. Runsink, Streeklaboratorium Zeeland, Middelburg; C.A. Seldenrijk, Stichting Sint Antonius Ziekenhuis, Nieuwegein; M. Mravunac, CanisiusWilhelmina Ziekenhuis, Nijmegen; W.S. Kwee, Laurentius Ziekenhuis, Roermond; H. van Dekken, Daniel den Hoed Kliniek, Rotterdam; J.C. Verhaar and N.A.L. van Kaam, Stichting Pathan, Rotterdam; H. van Dekken, Academisch Ziekenhuis Rotterdam, Dijkzigt; R.W.M. Giard, Sint Clara Ziekenhuis, Rotterdam; H. Beerman, Zuiderziekenhuis, Rotterdam; A.A.M. van der Wurff, Sint Elisabeth Ziekenhuis, Tilburg; M.E.I. Schipper, Universitair Medisch Centrum, Utrecht; H.M. Ruitenberg, Diakonessenhuis, Utrecht; R.F.M. Schapers, Stichting Pathologisch Laboratorium, Venlo; A.P. Willig, Sint Jans-Gasthuis, Weert; and A.G. Balk, Stichting Ziekenhuis De Heel, Zaandam; Radiotherapists: E.H.J.M. Rutten, Medisch Centrum Alkmaar; D. Gonzalez Gonzalez and G. van Tienhoven, Academisch Medisch Centrum, Amsterdam; B.J. Slotman and J.A. Langendijk, Academisch Ziekenhuis Vrije Universiteit, Amsterdam; G.M.M. Bartelink and B.M.P. Aleman, Antoni van Leeuwenhoekziekenhuis, Amsterdam; A.H. Westenberg, Arnhems Radiotherapeutisch Instituut, Arnhem; J. Pomp, Reinier de Graaf Gasthuis, Delft; C.C.E. Koning and R.G.J. Wiggenraad, Medisch Centrum Haaglanden, Den Haag; F.M. Gescher, Ziekenhuis Leyenburg, Den Haag; J.J.F.M. Immerzeel and A.C.A. Mak, Radiotherapeutisch Instituut Stedendriehoek en Omstreken, Deventer; J.G. Ribot and H. Martijn, Catharina Ziekenhuis, Eindhoven; D.F.M. de Haas-Kock, Stichting Radiotherapeutisch Instituut Limburg, Heerlen; G. Botke and A. Slot, Radiotherapeutisch Instituut Friesland, Leeuwarden; E.M. Noordijk, Leids Universitair Medisch Centrum, Leiden; P. Lambin, Academisch Ziekenhuis Maastricht; J. Hoogenhout, Academisch Ziekenhuis Nijmegen Sint Radboud, Nijmegen; P.C. Levendag and P.E.J. Hanssens, Daniel den Hoed Kliniek, Rotterdam; G.S.J. Bunnik and K.A.J. de Winter, Dokter Bernard Verbeeten Instituut, Tilburg; J.J. Batterman and H.K. Wijrdeman, Universitair Medisch Centrum, Utrecht; and J.M. Tabak and M.F.H. Dielwart, Zeeuws Radiotherapeutisch Instituut, Vlissingen. Other Countries - J.C. Pector, Institut Jules Bordet, Belgium; J. van de Stadt, Université Libre de Bruxelles, Hospital Erasme, Belgium; P.T. Phang and J.K. MacFarlane, St. Paul's Hospital, Canada; P. Teniere, Hôpital Charles Nicolle, France; J.R. Delpero, Institut J. Paoli et I. Calmettes, France; B. Sastre, Hôpital Sainte-Marguerite, France; B. Nordlinger and C. Penna, Centre Hospitalier Universitaire Ambroise Pare, France; B. Gerdes and B. Stinner, Klinikum der Philips-Universität, Germany; P. Delrio and V. Parisi, Istituto Nazionale per lo Studio e la Cura dei Tumori, Italy; S. Pucciarelli, Universita di Padova, Italy; J. Guimaraes dos Santos, Instituto Portuguẽs de Ontologica do Porto, Portugal; A. Nihlberg and O. Bendtsen, Falu Lasarett, Sweden; G. Lindmark, Helsingborgs Lasarett, Sweden; A. Törnqvist and T. Hallgren, Centralsjukhuset, Sweden; R. Sjödahl and O. Hallbook, University of Linköping, Sweden; M. Bohe and H. Jiborn, Allmäna Sjukhuset, Sweden; E. Nilsson, Lasarettet i Motala, Sweden; H Krook and G. Arbman, Landstinget i Östergötland, Sweden; J. Rutegård, Örnsköldsvik Hospital, Sweden; B. Sandzén, Umeå University Hospital, Sweden; W. Graf, Akademiska Sjukhuset, Sweden; K. Smedh, Centralhospital, Sweden; K. Johansson, Västerviks Sjukhus, Sweden; and R.J. Heald and B.J. Moran, North Hampshire Hospital, United Kingdom.

\section{REFERENCES}

1. Wiggers T, de Vries MR, Veeze-Kuypers B. Surgery for local recurrence of rectal carcinoma. Dis Colon Rectum 1996;39:323-8.

2. Holm T, Cedermark B, Rutqvist LE. Local recurrence of rectal adenocarcinoma after 'curative' surgery with and without preoperative radiotherapy. Br J Surg 1994;81:452-5.

3. Harnsberger JR, Vernava VM III, Longo WE. Radical abdominopelvic lymphadenectomy: historic perspective and current role in the surgical management of rectal cancer. Dis Colon Rectum 1994;37:73-87.

4. Phillips RK, Hittinger R, Blesovsky L, Fry US, Fielding LP. Local recurrence following 'curative' surgery for large bowel cancer. I. The overall picture. Br J Surg 1984;71:12-6.

5. Kapiteijn E, Marijnen C, Colenbrander AC, et al. Local recurrence in patients with rectal cancer, diagnosed between 1988 and 1992: a population-based study in the west Netherlands. Eur J Surg Oncol 1998;24:528 35 .

6. Frykholm GJ, Glimelius B, Pahlman L. Preoperative or postoperative irradiation in adenocarcinoma of the rectum: final treatment results of a randomized trial and an evaluation of late secondary effects. Dis Colon Rectum 1993;36:564-72.

7. Swedish Rectal Cancer Trial. Improved survival with preoperative radiotherapy in resectable rectal cancer. N Engl J Med 1997;336:980-7. [Erratum, N Engl J Med 1997;336:1539.]

8. Camma C, Giunta M, Fiorica F, Pagliaro L, Craxi A, Cottone M. Pre operative radiotherapy for resectable rectal cancer: a meta-analysis. JAMA 2000;284:1008-15.

9. MacFarlane JK, Ryall RD, Heald RJ. Mesorectal excision for rectal cancer. Lancet 1993;341:457-60.

10. Enker WE, Thaler HT, Cranor ML, Polyak T. Total mesorectal excision in the operative treatment of carcinoma of the rectum. J Am Coll Surg 1995;181:335-46.

11. Aitken RJ. Mesorectal excision for rectal cancer. Br J Surg 1996;83: 214-6.

12. Martling AL, Holm T, Rutqvist LE, Moran BJ, Heald RJ, Cedermark B. Effect of a surgical training programme on outcome of rectal cancer in the County of Stockholm. Lancet 2000;356:93-6.

13. Dahlberg M, Glimelius B, Pahlman L. Changing strategy for rectal cancer is associated with improved outcome. Br J Surg 1999;86:379-84

14. Havenga K, Enker WE, Norstein J, et al. Improved survival and local control after total mesorectal excision or D3 lymphadenectomy in the treatment of primary rectal cancer: an international analysis of 1411 patients. Eur J Surg Oncol 1999;25:368-74.

15. Myerson RJ, Michalski JM, King ML, et al. Adjuvant radiation therapy for rectal carcinoma: predictors of outcome. Int J Radiat Biol Phys 1995; 32:41-50.

16. McArdle CS, Hole D. Impact of variability among surgeons on postoperative morbidity and mortality and ultimate survival. BMJ 1991;302: 1501-5.

17. Hermanek P, Wiebelt H, Staimmer D, Riedl S. Prognostic factors of rectum carcinoma - experience of the German Multicentre Study SGCRC. Tumori 1995;81:Suppl:60-4.

18. Quirke P, Durdey P, Dixon MF, Williams NS. Local recurrence of rectal adenocarcinoma due to inadequate surgical resection: histopathological study of lateral tumour spread and surgical excision. Lancet 1986;2:996-9. 19. Kapiteijn E, Kranenbarg EK, Steup WH, et al. Total mesorectal excision (TME) with or without preoperative radiotherapy in the treatment of primary rectal cancer: prospective randomised trial with standard operative and histopathological techniques. Eur J Surg 1999;165:410-20.

20. Nagtegaal ID, Kranenbarg EK, Hermans J, van de Velde CJ, van Krieken JH. Pathology data in the central databases of multicenter randomized trials need to be based on pathology reports and controlled by trained quality managers. J Clin Oncol 2000;18:1771-9.

21. Carlsson U, Lasson A, Ekelund G. Recurrence rates after curative surgery for rectal carcinoma, with special reference to their accuracy. Dis Colon Rectum 1987;30:431-4. 
22. Rao AR, Kagan AR, Chan PM, Gilbert HA Nussbaum H, Hintz BL. Patterns of recurrence following curative resection alone for adenocarcino$\mathrm{ma}$ of the rectum and sigmoid colon. Cancer 1981;48:1492-5.

23. Marijnen CA, Nagtegaal ID, Kranenbarg EK, et al. No downstaging after short-term preoperative radiotherapy in rectal cancer patients. J Clin Oncol 2001;19:1976-84.

24. Fletcher GH. Hypofractionation: lessons from complications. Radiother Oncol 1991;20:10-5.

25. Cedermark B, Johansson H, Rutqvist LE, Wilking N. The Stockholm I trial of preoperative short term radiotherapy in operable rectal carcinoma: a prospective randomized trial. Cancer 1995;75:2269-75.

26. Goldberg PA, Nicholls RJ, Porter NH, Love S, Grimsey JE. Long- term results of a randomised trial of short-course low-dose adjuvant preoperative radiotherapy for rectal cancer: reduction in local treatment failure. Eur J Cancer 1994;30A:1602-6.

27. Initial report from a Swedish multicentre study examining the role of preoperative irradiation in the treatment of patients with resectable rectal carcinoma: Swedish Rectal Cancer Trial. Br J Surg 1993;80:1333-6.

28. Dahlberg M, Glimelius B, GrafW, Pahlman L. Preoperative irradiation affects functional results after surgery for rectal cancer: results from a randomized study. Dis Colon Rectum 1998;41:543-9.

Copyright (C) 2001 Massachusetts Medical Society.

646 • N Engl J Med, Vol. 345, No. 9 • August 30, $2001 \cdot$ www.nejm.org 